\title{
Faculty Knowledge, Awareness, Value, and Self-Efficacy in Teaching Systems Thinking to Nursing Students: A Pilot Study
}

\author{
Alaa Nabil Mahsoon ${ }^{1,2^{*}}$ and Mary Dolansky ${ }^{1}$ \\ ${ }^{1}$ Case Western Reserve University, USA
}

${ }^{2}$ King Abdulaziz University, Saudi Arabia

*Corresponding author: Alaa Mahsoon, PhD, MSN, RN, Case Western Reserve University, USA and King Abdulaziz University, Saudi Arabia, Tel: +9665-9560-6090

\begin{abstract}
Background: Systems thinking is a core competency in nursing education. The assessment of knowledge, awareness and value of, and self-efficacy for teaching systems thinking among faculty is an important step to plan faculty development process.

Method: A 17-item faculty questionnaire was developed to assess the knowledge, awareness and value of, and self-efficacy for teaching systems thinking to nursing students as a part of a pilot study. The questionnaire was administered to the nursing faculty at a nursing school in the Midwest region (response rate: 19.49\%; 20/92).

Results: All participants had partial knowledge and awareness of systems thinking. Most of them valued systems thinking and considered it an important inclusion in the nursing course. Although educators were ready for this, they were only moderately comfortable in teaching systems thinking at the time of the survey.

Conclusions: Faculty training on systems thinking is proposed, and specific techniques are suggested. Conducting a faculty assessment survey is an important step in tailoring the faculty development process.
\end{abstract}

\section{Keywords}

Systems thinking, Nursing education, Quality and safety

\section{Background}

The Institute of Medicine (IOM) published the report To Err is Human to alert medical professionals on the centrality of medical errors to patient safety [1]. The IOM report (1999) estimated that 98,000 hospitalized individuals die annually as a result of preventable medical errors [1]. Medical errors do not occur because of individual carelessness, but rather from faulty systems, processes, and conditions within a complex healthcare system [1]. It was not until the publication of the IOM report (1999) that a systems approach was recognized as critical for patient safety across all healthcare domains. Moving healthcare professionals to consider the whole system is referred to as "systems thinking". Systems thinking is defined as the "ability to recognize, understand, and synthesize the interactions and interdependencies in a set of components designed for a specific purpose to view problems as part of a chain of events of a larger system, rather than as independent events" [2]. The hallmark of systems thinking is the holistic analysis of patient-centered care, which addresses the safety of patients within the whole organization [3]. Systems thinking should be emphasized in practice, education and in health research arena [4].

The importance of systems thinking incorporation within the education of multidisciplinary learning organizations is highlighted that by giving away the idea of pulling everything apart to solve a problem, we can build a learning organization in which everything is interconnected and people learn how to learn and how to work together to maximize efficient outcomes [5]. The Accreditation Council for Graduate Medical Education (2001) identified systems-based practice as a core competency in medical education used in order to better understand healthcare complexity, analyze systems-related errors, and improve related outcomes [6]. Further, The Massachusetts Nurse of the Future Core Competency Model also considered systems-based practice as

Citation: Mahsoon AN, Dolansky M (2019) Faculty Knowledge, Awareness, Value, and Self-Efficacy in Teaching Systems Thinking to Nursing Students: A Pilot Study. Int Arch Nurs Health Care 5:126. doi. org/10.23937/2469-5823/1510126

Accepted: June 04, 2019: Published: June 06, 2019

Copyright: (c) 2019 Mahsoon AN, et al. This is an open-access article distributed under the terms of the Creative Commons Attribution License, which permits unrestricted use, distribution, and reproduction in any medium, provided the original author and source are credited. 
one of the 11 core competencies for nurses in acquiring the essential knowledge, attitudes, and skills to provide safe care [7]. While the inclusion of systems-based practice competency has been included in healthcare education, it is presently unclear how the achievement of systems-based competency is assessed. While systems thinking has been identified as the cornerstone of system-based practice as well as it can be taught, learned, changed, and measured [2], is suggested to be a prerequisite skill for systems-based practice [8-11].

Systems thinking is a cognitive skill essential to identifying the underlying elements of a system and understanding their behaviors and nonlinear interrelationship for specific purposes, which makes it useful for appropriately predicting and adjusting system outcomes [12]. Systems thinking as a key element in quality and safety should be given emphasis in education and healthcare research $[3,4]$.

\section{Literature Review}

Systems thinking has been established as an essential competency for all public health graduate students and a key concept in healthcare curriculum in the United States $[13,14]$. Systems thinking was identified as a key to quality and safety competencies by the Quality and Safety Education for Nurses (QSEN) institute which was funded by the Robert Wood Johnson Foundation in 2005. It is likely that if nurses engage in better systems thinking, they will achieve greater improvements in patient outcomes. The usefulness of systems thinking among nurses as a key component in safety performance lies in their ability to identify potential system malfunctions as well as ways to correct these malfunctions. Dolansky and Moore [11] suggested that systems thinking must be incorporated into care by shifting the approach from individual patient care to care at the systems level [11]. Nurses should use systems thinking to recognize, understand, and synthesize the interactions and interdependencies between their behavior and the complex, unpredicted events in the system in which they work [2]. Similar evidence highlighting the benefits of using systems thinking approach was found in research studies presented below. In the United States (U.S.), 120 medical students have been exposed to simulated case studies to practice on learning about what causes preventable error using system-based thinking skill and materials [15]. Aboumatar, et al. [15] reported that including systems thinking in healthcare safety curriculum increases systems awareness of safety knowledge, system-based thinking in practice, and self-efficacy of medical students. In a pilot study on 84 undergraduate nursing students conducted by Fura \& Wisser [16], a systems-thinking approach was integrated into patient safety education. After a four-hour educational session on patient safety, care delivery, and medication errors, an improvement in the overall systems thinking was reported in the post-test assessment among the students
[16]. Hwang and Park [17] conducted a cross-sectional study on 407 nurses, assessing their systems thinking level and the corresponding association with involvement and reporting of adverse events. They found that nurses had a moderate level of systems thinking with a mean score of 54.5 out of 80 and nurses with higher systems thinking scores were more likely to report medical errors and less likely to experience the occurrence of adverse event [17]. Further, a mini qualitative study conducted in the U.S. by Young [18] integrated role-play simulation and systems thinking as a competency measure for pre-licensure nurses, for enhancing systems thinking to encourage high-quality care among future nurses [18]. Although these studies have indicated the importance of teaching and integrating systems thinking into the health curricula, no studies have assessed how ready and comfortable nursing educators are with respect to teaching systems thinking, and to what extent they value the inclusion of systems thinking in nursing education. Therefore, this study aimed to propose a faculty assessment of teaching systems thinking to examine the present state of incorporating systems thinking into nursing courses.

\section{Method}

A questionnaire of the knowledge, awareness and value of and self-efficacy for teaching systems thinking to nursing students was electronically distributed to all nursing faculty members ( $N=92$ ) of a nursing school at a university in the Midwest United States. The research was approved by the university's Institute Review Board, and the distribution of the questionnaire was approved by the Associate Dean for Academic Affairs. The questionnaire assessed the faculty members' knowledge, awareness and value of, and self-efficacy for teaching systems thinking. Participants answered a total of 17 questions including six questions on demographic characteristics and four open-ended questions. The survey assessed systems thinking of nursing educators across four domains, which included knowledge ( 3 items), awareness ( 1 item), value ( 2 items), and self-efficacy ( 4 items). The tool utilized a variety of response types including Likert scale, yes or no answers, and open-ended answers, based on the nature of the question. The questionnaire was assessed for face validity, as the authors who developed the questionnaire items are experts in systems thinking science. Data were collected electronically over a two-month period. Participation was anonymous and voluntary and 20 participants completed the questionnaire. The survey completion took approximately 15 minutes.

\section{Results}

Data were analyzed using the latest version of the Statistical Package for the Social Sciences (SPSS 26.0). The demographic characteristics of the sample showed that the majority of the sample were female participants and the ages of the participants ranged from 30 to 
Table 1: Sample characteristics $(n=20)$.

\begin{tabular}{|l|l|}
\hline Variables & $n(\%)$ \\
\hline Gender & $4(20)$ \\
\hline Male & $16(80)$ \\
\hline Age range (years) & $4(20)$ \\
\hline $30-39$ & $2(10)$ \\
$40-49$ & $6(30)$ \\
\hline $50-59$ & $8(40)$ \\
\hline $60-69$ & \\
\hline Teaching level & $6(30)$ \\
\hline Graduate & $6(30)$ \\
\hline Undergraduate & $8(40)$ \\
\hline Both & \\
\hline Highest academic degree & $3(15)$ \\
\hline Master of Science & $9(45)$ \\
\hline Doctor of Philosophy (PhD) & $8(40)$ \\
\hline Doctor of Nursing (DNP) & $19(78.9)$ \\
\hline Heard of systems thinking & $1(5)$ \\
\hline Yes & $4(21.1)$ \\
\hline No & \\
\hline Exposed to systems thinking material in education \\
\hline Yes & \\
\hline No & \\
\hline
\end{tabular}

Table 2: Sample characteristics $(\mathrm{N}=16)$.

\begin{tabular}{|l|l|l|}
\hline Characteristics & Mean (SD) & Range \\
\hline Experience (years) & $15.25(10.77)$ & $1-32$ \\
\hline
\end{tabular}

69 years. Many participants taught both undergraduate and graduate courses, and the number of participants who taught graduate or undergraduate course was proportionate for both groups. A majority of participants had either a Doctor of Philosophy degree or a Doctor of Nursing degree, while the remaining of the participants had a Master of Science degree. All participants had heard of systems thinking except one person; $75 \%$ of the participants were exposed to resource material on systems thinking. Years of experience in nursing education ranged from 1 to 32 , with a mean of 15.25 years (SD $=10.77$ ). Table 1 and Table 2 present a summary of the sample characteristics.

The results of the data analysis of the value, readiness, and comfort levels in teaching and incorporating systems thinking are presented in Table 3 . Most of the participants valued the importance of systems thinking and agreed that it should be incorporated into the nursing courses, while the remaining participants considered it moderately important. Moreover, the majority of the participants believed that systems thinking help nurses provide safe and quality care, whereas the others believed that it might be helpful. The readiness and com-
Table 3: Data analysis summary $(n=19)$.

\begin{tabular}{|l|l|}
\hline Variables & $n(\%)$
\end{tabular}

Systems thinking is appropriate to be incorporated into the nursing courses

\begin{tabular}{|l|l|}
\hline Yes & $17(89.4)$ \\
Maybe & $1(5.3)$ \\
No & $1(5.3)$ \\
\hline
\end{tabular}

Importance of systems thinking to be incorporated into nursing courses

Important

Moderately Important

Systems thinking will help nurses provide high-quality and safe care

\begin{tabular}{|l|l|}
\hline Yes & $14(73.7)$ \\
Maybe & $5(26.3)$
\end{tabular}

How ready are you to include systems thinking into your nursing courses?

\begin{tabular}{l|l}
\hline Extremely ready & $7(36.8)$ \\
Very ready & $4(21.1)$ \\
Moderately ready & $5(26.3)$ \\
Slightly ready & $1(5.3)$ \\
Not at all ready & $2(10.5)$
\end{tabular}

How comfortable are you in teaching topics that involve systems thinking?

\begin{tabular}{|l|l|} 
Extremely comfortable & $4(21.1)$ \\
Moderately comfortable & $5(26.1)$ \\
Slightly comfortable & $4(21.1)$ \\
Neither comfortable nor uncomfortable & $4(21.1)$ \\
Uncomfortable & $2(10.6)$ \\
\hline
\end{tabular}

fort levels of the participants reflect their self-efficacy. The analysis of the participants' readiness to include systems thinking in their nursing courses indicated that participants who were very ready comprised a majority $(57.9 \%)$ of the sample. The remaining participants expressed being moderately ready $(26.3 \%)$ or slightly ready $(5.3 \%)$, and not ready $(10.5 \%)$. The analysis of participants' comfort level to teach systems thinking revealed that $22.1 \%$ were extremely comfortable, $26.3 \%$ were moderately comfortable, $21.1 \%$ were slightly comfortable; $21.1 \%$ were neither comfortable nor uncomfortable, and $10.6 \%$ were uncomfortable.

A qualitative analysis of the responses provides additional insight into the participants' knowledge, value and awareness of, and self-efficacy for systems thinking. To reflect the knowledge domain of the instrument, participants were asked to define systems thinking. Participants were considered to possess sufficient knowledge if they could define systems thinking as the "ability to recognize, understand, and synthesize the interactions and interdependencies in a set of components designed for a specific purpose to view problems as part of a chain of events of a larger system, rather than as independent events" [2]. Eighteen participants (90\%) responded to this question. Almost half (44.4\%; 8 out of 18 ) of the participants presented sufficient knowledge 
and provided similar definitions to the formal one:

"Systems thinking is a way of knowing how to understand a complex system and how the users interact with each other and the multiple dimensions of a complex system".

"Systems thinking is a holistic approach used in any area of study. It is an abstract way of thinking that requires a person to see a system as a whole rather than a sum of its parts. The parts (or elements) are interconnected (or synergistic) and work together toward a goal. For example, in pediatric nursing, I see the child in the context of a family system".

"...It's a way to analyze how something is working as a whole without breaking it down into each individual part. It looks at relationships when trying to resolve problems and can use feedback and simulation to help problems solve".

Some of the participants $(27.7 \%$; 5 out of 18$)$ had partial knowledge as they focused their definitions on only one attribute of systems thinking that is the interrelationship between the system's components within a system. Some of the responses were as follows:

"The ability to think beyond the self and the individual to consider the connections to others and the environment".

"How individual parts of the system relate to the overall larger system".

"Systems thinking is considering/understanding how all the parts of an entity work together and how they are interconnected".

The remaining $16.6 \%$ of the participants were unsure of what systems thinking is, and one participant (5.5\%) focused on the outcome of using systems thinking. While less than half ( $44.4 \%$ ) of the participants captured the essence of systems thinking, the analysis of these definitions reveals that the faculty need further engagement with the subject in order to understand the core concepts of systems thinking.

The next area of interest was the participants' value and awareness of systems thinking based on their general understanding of systems thinking as educators. The majority of the responses $(80 \% ; 16$ out of 20$)$ revealed participants held favorable, although varied, views, about systems thinking. More than half (56\%) of the participants valued the integration of systems thinking into nursing education without specifying its exact role. They stated that systems thinking might be effective to foster leadership, evidence-based practice, critical thinking, and clinical reasoning. A proportion of the participants (25\%) linked the value of systems thinking to quality and safety, cost-effectiveness, and collaboration and a few participants (18\%) believed that systems thinking could help navigate through the complexities of the healthcare system.
Some of the specific responses were as follows:

"It is the wave of the future. Instead of isolated silos, it is important how health care and its various components interact with each other. Interdisciplinary patient care improves quality and outcomes".

"Absolutely necessary to enable students to begin to understand the complexity of everything that contributes to a particular phenomenon, while hard for many students to grasp-especially the idea/role of complexity science - teaching systems thinking/science helps them to begin thinking more broadly and not so locally or simply".

Next, the participants' strategies and experiences on methods to incorporate systems thinking into nursing courses was investigated. The results showed that the current strategies included the use of large-group simulations, case studies, root-cause analysis in practice and classroom, safety and quality improvement, project planning, and analysis of complex data systems. Sixteen participants $(80 \%)$ responded to this question. Some of the specific responses included:

"In the informatics classes that I teach, the students read an informatics case study, do an analysis of the situation, and develop systems-based solutions to the issue. The students then critique the solutions in terms of how well each solution applies a systems-based framework".

"I am currently integrating some large-group simulations that require students to look at not only physical assessment but also analyze patterns of communication, opportunities for systems improvement, and the chance to promote patient-centered care".

The analysis of the 18 participants (90\%) suggested strategies indicated that case studies discussion in class or post conference, root-cause analysis, and interdisciplinary development of care plans could be used in order to integrate systems thinking into their nursing courses. The proposed methods were valid and realistic and the responses from the participants included the following:

"Integrate at least one systems thinking slide into each PowerPoint presentation in order to keep systems thinking on the radar. Use case studies with small group discussion and a report for the entire group. Encourage student reflection on systems thinking".

"As a post-clinical conference, nursing instructors could guide students through a root-cause analysis of an actual or fictional patient error. Students would be guided toward an analysis of the outcome based on the larger medical system".

\section{Discussion}

The findings reveal that nursing educators have a 
partial awareness and knowledge of systems thinking. However, their inclusion of systems thinking in the nursing course is lacking. Despite the fact that the faculty valued systems thinking and agreed that its inclusion in nursing courses is important, their readiness and comfort regarding the integration of systems thinking into nursing courses were not at the desired level. This might be because systems thinking in nursing education is still an abstract and novel concept. However, the educators regardless of their education level and years of experience had excellent ideas on how to include systems thinking in their courses, which reflects their awareness of how systems thinking can be beneficial to improve the holistic analysis of a situation.

It is apparent from the results that the educators were aware of the value of systems thinking in contemporary nursing, having linked it to several positive outcomes [19]. Moreover, the strategies that they were currently using, such as simulations, case studies, and root-cause analysis, support a systems approach to the analysis of problems and development of solutions $[20,21]$. However, there is a clear need to bolster educators' readiness and comfort in integrating systems thinking concepts in their courses. This could be done by providing institutional support, in the form of training and equipment or other support educators might require for the effective integration of systems thinking. Efforts to improve systems thinking in nursing courses should focus on empowering the educators as they showed awareness of, interest in, and appreciation for systems thinking. Furthermore, there is a need to broaden educators' knowledge and capacity to employ different educational techniques that support systems thinking because the educators currently use a small set of systems thinking strategies. Educators need organized thoughts and guides to maximize the effects of applying systems thinking. The System Awareness Model (SAM) developed by Phillips and Stalter [3] is an excellent conceptual framework with seven phases for different levels of nursing students-beginner, intermediate, and advanced systems thinkers-that can be adapted to foster the integration of systems thinking into nursing education.

\section{Limitation}

There are some limitations to this pilot study. The study was conducted on one school using convenience sampling, which reflected a very low response rate to the questionnaire. The low response rate and the one setting sample limited the generalizability of the findings. In addition, there is a potential for recall bias with any self-reported measure in that the participants tend to overestimate their answers to seek social desirability. The instrument was subjective and developed only for the purpose of this pilot study. Further psychometric testing is required in order to determine the reliability and validity of the instrument and to provide unbiased more accurate results.

\section{Conclusion}

The present study was a first step in obtaining insights into the current status of incorporating systems thinking into nursing courses at the faculty level. From the present pilot study, it is evident that faculty have partial knowledge and awareness of systems thinking and value its role in in the curriculum of nursing students. Our results can provide nurse educators with an understanding of the benefits and ways of including systems thinking materials within different nursing courses. The results may encourage beginning conversations for regulatory agencies that oversee academic nursing to mandate and monitor the inclusion of systems thinking in the curriculum. To further enhance evidence-based practice, there is a need for the study replication with using an enhanced tool and including larger sample from different educational settings to evaluate the effectiveness of applying systems thinking in nursing educational courses and understanding how this translates to clinical settings.

\section{References}

1. Kohn LT, Corrigan JM, Donaldson MS (2000) To err is human: Building a safer health system. National Academies Press, Washington (DC).

2. Moore S, Dolansky M, Singh M, Plamieri P, Alemi F (2011) The systems thinking scale: A measure of systems thinking. Case Western Reserve University, 1-27.

3. Phillips JM, Stalter AM (2016) Integrating systems thinking into nursing education. J Contin Educ Nurs 47: 395-397.

4. Swanson RC, Cattaneo A, Bradley E, Chunharas S, Atun R, et al. (2012) Rethinking health systems strengthening: Key systems thinking tools and strategies for transformational change. Health Policy Plan 27: 54-61.

5. Senge MP (2006) The fifth discipline: The art and practice of the learning organization. Doubleday, New York, NY.

6. Batalden $P$, Leach D, Swing S, Dreyfus H, Dreyfus S (2002) General competencies and accreditation in graduate medical education. Health Aff 21: 103-111.

7. Sroczynski M, Gravlin G, Route PS, Hoffart N, Creelman $P$ (2011) Creativity and connections: The future of nursing education and practice: The Massachusetts initiative. J Prof Nurs 27: e64-e70.

8. Adam T, de Savigny D (2012) Systems thinking for strengthening health systems in LMICs: Need for a paradigm shift. Health Policy Plan 27: 1-3.

9. Bleich MR (2014) Developing leaders as systems thinkersPart III. J Contin Educ Nurs 45: 246-248.

10. Colbert CY, Ogden PE, Ownby AR, Bowe C (2011) Systemsbased practice in graduate medical education: Systems thinking as the missing foundational construct. Teach Learn Med 23: 179-185.

11. Dolansky MA, Moore SM (2013) Quality and safety education for nurses (QSEN): The key is systems thinking. Online J Issues Nurs 18: 1.

12. Arnold RD, Wade JP (2015) A definition of systems thinking: A systems approach. Procedia Computer Science 44: 669678. 
13. Calhoun JG, Ramiah K, Weist EM, Shortell SM (2008) Development of a core competency model for the master of public health degree. Am J Public Health 98: 1598-1607.

14. Norman CD (2013) Teaching systems thinking and complexity theory in health sciences. J Eval Clin Pract 19: 1087-1089.

15. Aboumatar HJ, Thompson D, Wu A, Dawson P, Colbert J, et al. (2012) Development and evaluation of a 3-day patient safety curriculum to advance knowledge, self-efficacy and system thinking among medical students. BMJ Qual Saf 21: 416-422.

16. Fura LA, Wisser KZ (2017) Development and evaluation of a systems thinking education strategy for baccalaureate nursing curriculum: A pilot study. Nurs Educ Perspect 38: 270-271.

17. Hwang JI, Park HA (2017) Nurses' systems thinking competency, medical error reporting, and the occurrence of adverse events: A cross-sectional study. Contemp Nurse 53: $622-632$.

18. Young $J$ (2018) Using a role-play simulation game to promote systems thinking. J Contin Educ Nurs 49: 10-11.

19. Phillips JM, Stalter AM, Dolansky MA, Lopez GM (2016) Fostering future leadership in quality and safety in health care through systems thinking. J Prof Nurs 32: 15-24.

20. Carter AG, Creedy DK, Sidebotham M (2016) Efficacy of teaching methods used to develop critical thinking in nursing and midwifery undergraduate students: A systematic review of the literature. Nurse Educ Today 40: 209-218.

21. Rosenkränzer F, Hörsch C, Schuler S, Riess W (2017) Student teachers' pedagogical content knowledge for teaching systems thinking: Effects of different interventions. International Journal of Science Education 39: 1932-1951. 